\title{
Papers
}

\section{Value of routine funduscopy in patients with hypertension: systematic review}

Bert-Jan H van den Born, Caroline A A Hulsman, Joost B L Hoekstra, Reinier O Schlingemann,

Gert A van Montfrans

\begin{abstract}
Objective To evaluate the additional value of funduscopy in the routine management of patients with hypertension.

Design Systematic review.

Participants Adults aged 19 or more with hypertensive retinopathy.

Data sources Medline, Embase, and the Cochrane Library from 1990.

Review methods Studies were included that assessed hypertensive retinopathy with blinding for blood pressure and cardiovascular risk factors. Studies on observer agreement had to be assessed by two or more observers and expressed as a $\kappa$ statistic. Studies on the association between hypertensive retinopathy and hypertensive organ damage were carried out in patients with hypertension. The association between hypertensive retinopathy and cardiovascular risk was carried out in unselected normotensive and hypertensive people without diabetes mellitus.
\end{abstract}

Results The assessment of microvascular changes in the retina is limited by large variation between observers. The positive and negative predictive values for the association between hypertensive retinopathy and blood pressure were low ( $47 \%$ to $72 \%$ and $32 \%$ to $67 \%$, respectively). Associations between retinal microvascular changes and cardiovascular risk were inconsistent, except for retinopathy and stroke. The increased risk of stroke, however, was also present in normotensive people with retinopathy. These studies did not adjust for other indicators of hypertensive organ damage.

Conclusion Evidence is lacking that routine funduscopy is of additional value in the management of hypertensive patients.

\section{Introduction}

Since 1939 the Keith, Wagener, and Barker classification has been used to assess retinal changes associated with hypertension. From the 1980s onwards, screening for hypertension and antihypertensive treatment have improved considerably and the severity and frequency of retinal changes associated with hypertension seem to have diminished. ${ }^{12}$ In the recent guidelines of the Joint National Committee and the European Society of Hypertension, funduscopy is still recommended as part of the routine examination of hypertensive patients, although its value is being questioned. ${ }^{3}$

We carried out a systematic search to determine the usefulness of routine funduscopy in hypertensive patients. Firstly, we reviewed the literature on the reliability of detecting the various retinal changes associated with hypertension. Then
Keith, Wagener, and Barker classification of hypertensive retinopathy

Grade I-slight or modest narrowing of the retinal arterioles, with an arteriovenous ratio $\geq 1: 2$

Grade II-modest to severe narrowing of retinal arterioles (focal or generalised), with an arteriovenous ratio $<1: 2$ or arteriovenous nicking

Grade III-bilateral soft exudates or flame-shaped haemorrhages Grade IV-bilateral optic nerve oedema

we reviewed articles published since 1990 on the prevalence of retinal changes and their association with blood pressure, other indicators of hypertensive organ damage, and cardiovascular morbidity and mortality. We excluded studies in patients with hypertensive urgencies and emergencies as this is a separate group in whom funduscopy provides essential information for diagnosis and treatment.

\section{Methods}

We systematically searched Medline, Embase, and the Cochrane Library for articles on hypertension and retinopathy published since 1990 in adults aged 19 or more. Two investigators (BJHvdB and $\mathrm{CAAH}$ ) independently carried out the search using the terms retinopathy, retinal arteriolar narrowing, arteriovenous nicking, AV nicking, arteriovenous ratio, or AV ratio, combined either with observer agreement, observer variability, or kappa, or with hypertension, blood pressure, microalbuminuria, left ventricular hypertrophy, intima-media thickness, stroke, myocardial infarction, ischaemic heart disease, or cardiovascular mortality.

We use the term hypertensive retinopathy to describe all retinal changes included in the Keith, Wagener, and Barker classification (box). We use the term retinal microvascular changes to refer to narrowing of the retinal arterioles and arteriovenous nicking (see figs $\mathrm{A}$ and $\mathrm{B}$ on bmj.com). The term retinopathy was originally used to denote soft exudates and flame-shaped haemorrhages only (see fig $\mathrm{C}$ on bmj.com), but in the studies reviewed here retinopathy also encompasses microaneurysms, blot haemorrhages, and hard exudates.

We included studies on the reliability of detecting changes to the retina if retinal photographs were independently assessed by

Figures showing retinal changes are on bmj.com 


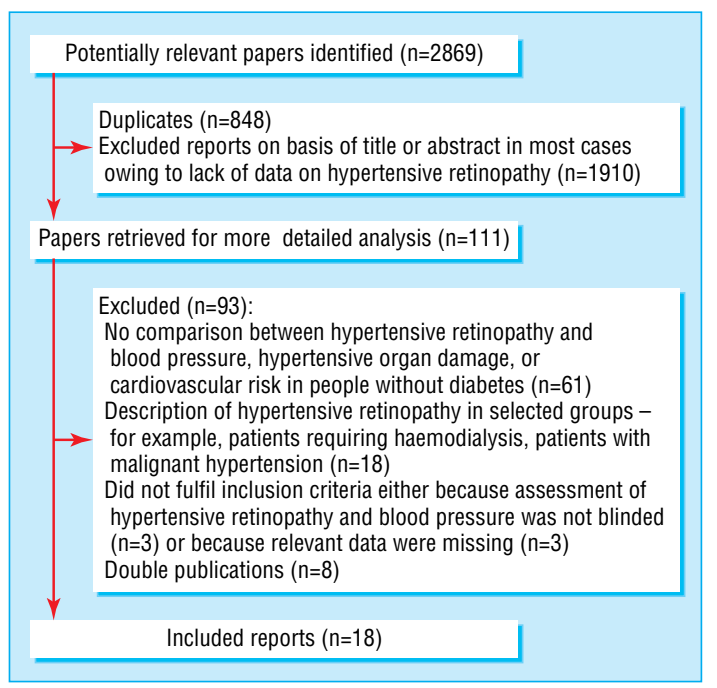

Fig 1 Selection of articles

two or more observers and if variability of detecting retinal changes associated with hypertension could be expressed as a $\kappa$ statistic.

For the association between retinal changes and hypertensive organ damage we included studies of hypertensive patients only. For the association between hypertensive retinopathy, cardiovascular risk, and blood pressure, we included population based or cohort studies with unselected normotensive and hypertensive people. In all studies, retinal changes had to be assessed without knowledge of blood pressure and cardiovascular risk factors, and diabetes mellitus had to be excluded, analysed separately, or adjusted for in multivariate analysis. Searches were carried out in the second half of October 2004.

\section{Statistical analysis}

We used $\kappa$ statistics to express the proportion of agreement for the various retinal changes associated with hypertension, correcting for agreement expected by chance. ${ }^{5}$ We included both weighted and unweighted $\kappa$ statistics, where weighted $\kappa$ provides a scaled probability score so that the sum of the weight equals the number of observations.

For the association between blood pressure and retinal changes we considered the various retinal changes as a diagnostic test for hypertension. We calculated sensitivity, specificity, and positive and negative predictive values. Pooled odds ratios were calculated for the association between hypertensive retinopathy and hypertensive organ damage. We used a random effects model to generate summary measures and confidence intervals. Heterogeneity was examined using the $\mathrm{I}^{2}$ statistic, which indicates the proportion of variability in the weighted mean differences attributable to heterogeneity. ${ }^{6}$ To assess the association between hypertensive retinopathy and cardiovascular risk, we took the relative risk after multivariate analysis.

\section{Results}

We identified 111 reports with possible data on the association between hypertensive retinopathy and blood pressure, hypertensive organ damage, and cardiovascular risk (fig 1).

\section{Variability in detecting retinal changes}

Six studies had data on interobserver agreement for hypertensive retinopathy using retinal photographs. We found no such data for direct funduscopy. One study was excluded because we could not calculate $\kappa$ statistics. ${ }^{7}$ The most extensive study on observer agreement for hypertensive retinopathy was the atherosclerosis risk in communities study in which three readers graded a random sample of 206 retinal photographs. ${ }^{8}$ Table 1 lists the $\kappa$ statistics of this and other studies. In these studies, interobserver agreement was fair or moderate for focal arteriolar narrowing ( $\kappa 0.3$ to 0.4 ) and arteriovenous nicking ( $\kappa 0.4$ to 0.6 ). Agreement was excellent for haemorrhages and exudates. A computerised grading method was used to assess the arteriovenous ratio. ${ }^{9}$ With this method, agreement was good (к 0.7 to 0.8 ).

\section{Retinal changes and blood pressure}

Four large population based studies examined the association between hypertensive retinopathy and blood pressure. ${ }^{12}{ }^{14-16}$ Hypertension was defined as the use of antihypertensive drugs, or history of hypertension or blood pressure $\geq 140 / 90 \mathrm{~mm} \mathrm{Hg}$ in the cardiovascular health study and atherosclerosis risk in communities study or $\geq 160 / 95 \mathrm{~mm} \mathrm{Hg}$ in the Beaver Dam eye study and Blue Mountains eye study.

In one study, age and sex standardised prevalence of hypertensive retinopathy was $12 \%$ in white Europeans and $18 \%$ in people of Afro-Caribbean origin..$^{10}$ Table 2 lists the prevalence of retinal abnormalities for the other studies.

The sensitivity for hypertensive retinopathy ranged from 3\% to $21 \%$, indicating a low prevalence of retinal abnormalities in hypertensive patients. In contrast, specificity ranged from $88 \%$ to $98 \%$, and therefore retinopathy was rarely observed in normotensive patients. The positive predictive value, or the chance of hypertension given the presence of hypertensive retinopathy, ranged from $47 \%$ to $70 \%$ for haemorrhages and exudates, $53 \%$ to $66 \%$ for arteriovenous nicking, and $49 \%$ to $72 \%$ for focal arteriolar narrowing (table 3). The negative predictive value, or the chance of normotension in the absence of hypertensive retinopathy, ranged from $43 \%$ to $67 \%$ for haemorrhages and exudates, $44 \%$ to $66 \%$ for arteriovenous nicking, and $32 \%$ to $59 \%$ for focal arteriolar narrowing. Diagnostic accuracy could not be assessed for the arteriovenous ratio as normal and abnormal values were not defined.

Table 1 Kappa statistics for hypertensive retinopathy in studies included in systematic review

\begin{tabular}{|c|c|c|}
\hline Type of retinal change and study & Unweighted $\kappa$ & Weighted $\kappa$ \\
\hline \multicolumn{3}{|l|}{ Any retinopathy: } \\
\hline Sharp et al ${ }^{10}$ & $\begin{array}{l}\text { Afro-Caribbeans } 0.72 \text {; } \\
\text { white Europeans } 0.75\end{array}$ & Not reported \\
\hline \multicolumn{3}{|l|}{ Haemorrhages and exudates: } \\
\hline $\begin{array}{l}\text { Atherosclerosis risk in } \\
\text { communities study }\end{array}$ & 0.76 & 0.76 \\
\hline Cardiovascular health study ${ }^{11}$ & 0.88 & Not reported \\
\hline Blue Mountains eye study ${ }^{12}$ & 0.90 & Not reported \\
\hline \multicolumn{3}{|l|}{ Arteriovenous nicking: } \\
\hline $\begin{array}{l}\text { Atherosclerosis risk in } \\
\text { communities study }^{8}\end{array}$ & 0.59 & 0.56 \\
\hline Cardiovascular health study ${ }^{11}$ & 0.43 & Not reported \\
\hline \multicolumn{3}{|l|}{ Focal arteriolar narrowing: } \\
\hline $\begin{array}{l}\text { Atherosclerosis risk in } \\
\text { communities study }\end{array}$ & 0.39 & 0.29 \\
\hline Cardiovascular health study ${ }^{11}$ & 0.31 & Not reported \\
\hline \multicolumn{3}{|l|}{ Arteriovenous ratio*: } \\
\hline $\begin{array}{l}\text { Atherosclerosis risk in } \\
\text { communities study }\end{array}$ & 0.73 & 0.79 \\
\hline Cardiovascular health study ${ }^{11}$ & 0.81 & Not reported \\
\hline Blue Mountains eye study ${ }^{13}$ & Not reported & 0.75 \\
\hline
\end{tabular}

${ }^{*}$ Computer assisted grading method. 
Table 2 Characteristics of studies of retinal changes in patients with hypertensive retinopathy. Values are numbers (percentages) unless stated otherwise

\begin{tabular}{|c|c|c|c|c|c|c|}
\hline \multirow[b]{2}{*}{ Study } & \multirow[b]{2}{*}{ No of participants } & \multirow[b]{2}{*}{ Age range (years) } & \multirow[b]{2}{*}{$\begin{array}{l}\text { Participants with } \\
\text { hypertension* }\end{array}$} & \multicolumn{3}{|c|}{ Retinal changes } \\
\hline & & & & $\begin{array}{l}\text { Focal arteriolar } \\
\text { narrowing }(\%)\end{array}$ & $\begin{array}{c}\text { Arteriovenous nicking } \dagger \\
(\%)\end{array}$ & $\begin{array}{l}\text { Haemorrhages and } \\
\text { exudates }(\%)\end{array}$ \\
\hline Cardiovascular health study ${ }^{14}$ & 2056 & $69-97$ & $1424(59)$ & 9.6 & 7.6 & 8.3 \\
\hline Beaver Dam eye study $^{1}$ & 4311 & $43-84$ & $1479(34)$ & 13.5 & 2.2 & 7.8 \\
\hline $\begin{array}{l}\text { Atherosclerosis risk in } \\
\text { communities study } \ddagger^{15}\end{array}$ & 10358 & $48-73$ & $4595(44)$ & 14.9 & 14.3 & 7.0 \\
\hline Blue Mountains eye study ${ }^{16}$ & 3614 & $43-86$ & $1656(46)$ & 7.9 & 8.9 & Not reported \\
\hline Blue Mountains eye study ${ }^{12}$ & 3275 & $\geq 49$ & $1447(44)$ & Not reported & Not reported & 9.9 \\
\hline
\end{tabular}

*Use of antihypertensive drugs or a history of hypertension and blood pressure $\geq 140 / 90 \mathrm{~mm} \mathrm{Hg}$ in cardiovascular health study and atherosclerosis risk in communities study and $\geq 160 / 95 \mathrm{~mm} \mathrm{Hg}$ in the Beaver Dam eye study and Blue Mountains eye study.

†Different definitions used.

łIncluded patients with diabetes.

\section{Retinal changes and other indicators of organ damage}

Four studies examined the association between hypertensive retinopathy and echocardiographically determined left ventricular hypertrophy. ${ }^{17-20}$ One study failed to give the number of patients with events; however, the age and sex adjusted odds ratio (95\% confidence interval) for left ventricular hypertrophy was 1.92 (1.03 to 3.60) when retinopathy was present. ${ }^{21}$ Figure 2 gives details of the other studies. The pooled odds for left ventricular hypertrophy in the presence of hypertensive retinopathy was 2.22 (1.36 to 3.62), with little heterogeneity $\left(\mathrm{I}^{2}=29.1 \%\right)$. Two studies examined the association between hypertensive retinopathy and microalbuminuria (odds ratios 1.51, 0.84 to 2.68 and $4.98,1.97$ to 12.60$).{ }^{18}{ }^{22}$ We were unable to pool the data because of significant heterogeneity $\left(\mathrm{I}^{2}=78.3 \%\right)$. Three population based studies reported on the association between hypertensive retinopathy and intima-media thickness. ${ }^{11324}$ In the cardio- vascular health study and atherosclerosis risk in communities study only the presence of haemorrhages and exudates was associated with increased intima-media thickness. In the Rotterdam eye study a lower arteriovenous ratio was associated with an increased intima-media thickness; other retinal abnormalities were not reported. We were unable to compare the studies because different techniques were used to assess the associations.

\section{Retinal changes and cardiovascular risk}

Hypertensive retinopathy as an independent predictor of cardiovascular risk was examined in six different populations, totalling 16000 participants. We excluded two studies because blood pressure and patient history were known to the investigators before funduscopy. ${ }^{25}{ }^{26}$ Table 4 lists the association between hypertensive retinopathy and cardiovascular risk after adjustment in multivariate analysis. Risks of coronary heart disease,

Table 3 Diagnostic accuracy (\%) of various retinal changes for hypertension in studies included in systematic review

\begin{tabular}{|c|c|c|c|c|c|c|c|c|c|c|c|c|}
\hline \multirow[b]{2}{*}{ Study } & \multicolumn{4}{|c|}{ Generalised or focal arteriolar narrowing } & \multicolumn{4}{|c|}{ Arteriovenous nicking } & \multicolumn{4}{|c|}{ Haemorrhages and exudates } \\
\hline & Sensitivity & Specificity & $\begin{array}{l}\text { Positive } \\
\text { predictive } \\
\text { value }\end{array}$ & $\begin{array}{l}\text { Negative } \\
\text { predictive } \\
\text { value }\end{array}$ & Sensitivity & Specificity & $\begin{array}{l}\text { Positive } \\
\text { predictive } \\
\text { value }\end{array}$ & $\begin{array}{l}\text { Negative } \\
\text { predictive } \\
\text { value }\end{array}$ & Sensitivity & Specificity & $\begin{array}{l}\text { Positive } \\
\text { predictive } \\
\text { value }\end{array}$ & $\begin{array}{l}\text { Negative } \\
\text { predictive } \\
\text { value }\end{array}$ \\
\hline $\begin{array}{l}\text { Cardiovascular health } \\
\text { study }^{14}\end{array}$ & 12 & 94 & 72 & 46 & 9 & 94 & 66 & 44 & 9 & 94 & 70 & 43 \\
\hline Beaver Dam eye study $^{1}$ & 19 & 89 & 49 & 68 & 3 & 98 & 53 & 66 & 11 & 94 & 47 & 67 \\
\hline $\begin{array}{l}\text { Atherosclerosis risk in } \\
\text { communities } \\
\text { study }{ }^{15}\end{array}$ & 21 & 89 & 61 & 59 & 18 & 88 & 55 & 57 & 10 & 95 & 62 & 57 \\
\hline $\begin{array}{l}\text { Blue Mountains eye } \\
\text { study }^{16}\end{array}$ & 11 & 95 & 66 & 52 & 12 & 93 & 59 & 56 & $\begin{array}{c}\text { Not } \\
\text { reported }\end{array}$ & $\begin{array}{c}\text { Not } \\
\text { reported }\end{array}$ & $\begin{array}{c}\text { Not } \\
\text { reported }\end{array}$ & $\begin{array}{c}\text { Not } \\
\text { reported }\end{array}$ \\
\hline $\begin{array}{l}\text { Blue Mountains eye } \\
\text { study }{ }^{* 12}\end{array}$ & $\begin{array}{c}\text { Not } \\
\text { reported }\end{array}$ & $\begin{array}{c}\text { Not } \\
\text { reported }\end{array}$ & $\begin{array}{c}\text { Not } \\
\text { reported }\end{array}$ & $\begin{array}{l}\text { Not } \\
\text { reported }\end{array}$ & $\begin{array}{l}\text { Not } \\
\text { reported }\end{array}$ & $\begin{array}{c}\text { Not } \\
\text { reported }\end{array}$ & $\begin{array}{c}\text { Not } \\
\text { reported }\end{array}$ & $\begin{array}{c}\text { Not } \\
\text { reported }\end{array}$ & 13 & 93 & 58 & 57 \\
\hline
\end{tabular}

*People with diabetes included.

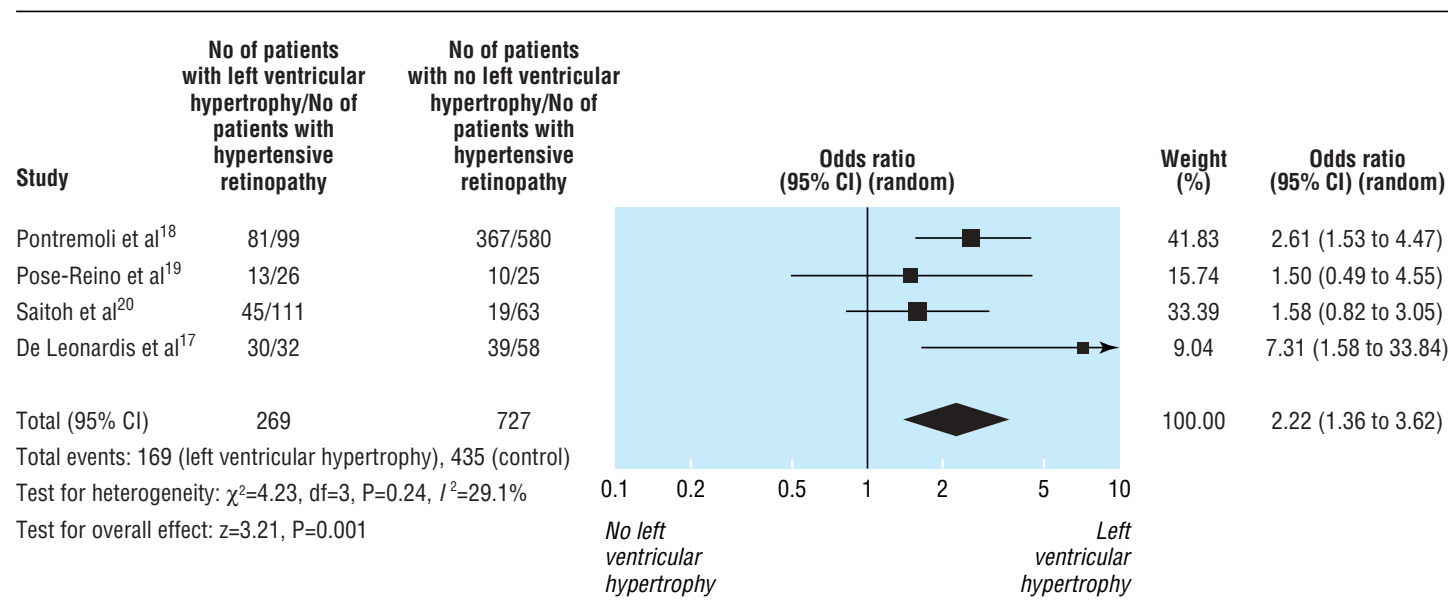

Fig 2 Odds ratios (95\% confidence intervals) for association between hypertensive retinopathy and left ventricular hypertrophy 
stroke, or death from cardiovascular disease differed with regard to retinal microvascular changes. Data on the association between retinopathy and stroke were more consistent: relative risk of stroke 3.4 (1.0 to 11.3) for men in the Shibata study and 2.6 (1.6 to 4.2) for men and women in the atherosclerosis risk in communities study. In the cardiovascular health study the odds ratio for stroke was 2.0 (1.1 to 3.6).

In the atherosclerosis risk in communities study and the Beaver Dam eye study, associations between retinal abnormalities and stroke were stratified by hypertension status. The relative risk of stroke in the atherosclerosis risk in communities study was 2.6 (1.2 to 5.6) with retinopathy and hypertension compared with 2.0 (0.5 to 8.4) in normotensive people. In the Beaver Dam eye study, the odds ratio for death from cardiovascular disease in people aged 43-74 with retinopathy and hypertension or diabetes, or both was 2.3 (1.2 to 4.2) compared with 1.5 (0.4 to 5.3) for those without hypertension and diabetes. The odds ratio for those aged 75-84 was 2.0 (1.0 to 4.0) if retinopathy and hypertension or diabetes, or both were present and 1.8 (0.4 to 8.4) if only retinopathy was present.

\section{Discussion}

In this systematic review we found limited additional value of funduscopy in the routine management of patients with hypertension, except in emergency cases.

The evaluation of hypertensive retinopathy is subject to large variability between observers, especially microvascular changes. Only haemorrhages and exudates can be reliably assessed in retinal photographs. We found no data on observer agreement using direct funduscopy. Recently, a computerised grading method has been developed to increase reproducibility of retinal microvascular changes, but this method is not widely available.

The low sensitivity of retinal abnormalities associated with hypertension indicates that hypertensive retinopathy is not common in hypertensive people. Less than half the retinal changes associated with hypertension cannot be explained by high blood pressure (low positive predictive value). In both the Beaver Dam eye study and the Blue Mountains eye study little difference was found in the presence of haemorrhages and exudates between normotensive and hypertensive people aged over $65 .{ }^{130}$ Various other conditions have been associated with hypertensive retinopathy, such as ethnicity, ${ }^{10}{ }^{21}$ smoking, ${ }^{23} 3132$ intima-media thickness, ${ }^{11}{ }^{23}{ }^{31}$ carotid plaque score ${ }^{31}{ }^{33}$ carotid artery stiffness, ${ }^{33}$ serum cholesterol concentration, ${ }^{23}{ }^{27}{ }^{32}$ diabetes, ${ }^{27}{ }^{32}$ and body mass index. ${ }^{27}{ }^{32}$ The high specificity indicates that hypertensive retinopathy is rare in patients with normal blood pressure. Half the people without hypertensive retinopathy, however, still have hypertension (low negative predictive value). So funduscopy cannot reliably determine whether a patient is normotensive or hypertensive.

The presence of hypertensive retinopathy doubles the risk of left ventricular hypertrophy. Data on the association between hypertensive retinopathy and microalbuminuria are inconsistent. Patients with haemorrhages and exudates have a higher intima-media thickness; for other retinal abnormalities this association is conflicting or absent.

Evidence that hypertensive retinopathy is an independent predictor of cardiovascular risk is based on two large studies in which hypertensive patients with retinal haemorrhages or exudates had a twofold higher risk of stroke. Neither study, however, examined or adjusted for other indicators of hypertensive organ damage (left ventricular hypertrophy, microalbuminuria, and intima-media thickness). Furthermore, the association between retinopathy and stroke was also observed in normotensive people, suggesting that besides blood pressure, other factors are responsible for these retinal changes.

A recent paper reported on the associations between hypertensive retinopathy, blood pressure, and mortality from cardiovascular disease. ${ }^{34}$ The authors found a strong association between hypertensive retinopathy and hypertension. Although this association was significant in most studies, the low predictive values we calculated indicate that funduscopy cannot reliably determine whether a patient has hypertension. Only for stroke is

Table 4 Associations between retinal changes and cardiovascular risk in studies included in systematic review. Values are relative risks $(95 \%$ confidence intervals) unless stated otherwise

\begin{tabular}{|c|c|c|c|c|c|c|c|c|c|}
\hline Study & Design & $\begin{array}{l}\text { Follow } \\
\text { up } \\
\text { (years) }\end{array}$ & End points & $\begin{array}{c}\text { No of } \\
\text { participants }\end{array}$ & $\begin{array}{l}\text { Arteriovenous } \\
\text { crossings }\end{array}$ & $\begin{array}{l}\text { Focal arteriolar } \\
\text { narrowing }\end{array}$ & $\begin{array}{l}\text { Generalised arteriolar } \\
\text { narrowing* }\end{array}$ & $\begin{array}{c}\text { Haemorrhages and } \\
\text { exudates }\end{array}$ & $\begin{array}{c}\text { Any retinopathy } \\
\text { (grade II or higher) } \dagger\end{array}$ \\
\hline $\begin{array}{l}\text { Beaver Dam } \\
\text { eye } \\
\text { study } \ddagger^{27}\end{array}$ & Case control & 10 & $\begin{array}{l}\text { Death from } \\
\text { coronary heart } \\
\text { disease or } \\
\text { stroke }\end{array}$ & 1611 & $1.0(0.5$ to 1.9$) \S$ & $\begin{array}{c}1.4 \\
(0.8 \text { to } 2.4) \S\end{array}$ & 1.5 (1.1 to 2.1$) \S$ & $1.8(1.2$ to 2.7$) \S$ & Not reported \\
\hline 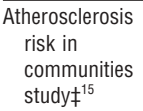 & $\begin{array}{l}\text { Population } \\
\text { based }\end{array}$ & 3 & Stroke & 10358 & 1.6 (1.0 to 2.5$)$ & 1.1 (0.7 to 1.8$)$ & 1.2 (0.7 to 2.3) & 2.6 (1.6 to 4.2 ) & Not reported \\
\hline 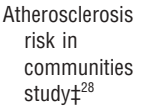 & $\begin{array}{l}\text { Population } \\
\text { based }\end{array}$ & 3 & $\begin{array}{l}\text { Coronary heart } \\
\text { disease }\end{array}$ & 9648 & Not reported & Not reported & $\begin{array}{l}\text { Men } 1.1(0.7 \text { to } 1.8), \\
\text { women } 2.2(1.0 \text { to } 4.6)\end{array}$ & $\begin{array}{c}\text { Men } 1.1 \text { ( } 0.6 \text { to } 2.3) \\
\text { women } 1.8 \text { ( } 0.8 \text { to } \\
4.2 \text { ) }\end{array}$ & Not reported \\
\hline $\begin{array}{l}\text { Cardiovascular } \\
\text { health } \\
\text { study } \|^{\star * 11}\end{array}$ & Cross sectional & - & $\begin{array}{l}\text { Coronary heart } \\
\text { disease }\end{array}$ & 2050 & 1.1 (0.7 to 1.6) & 0.9 (0.6 to 1.4) & 0.8 (0.6 to 1.0$)$ & 1.7 (1.2 to 2.6$)$ & Not reported \\
\hline $\begin{array}{l}\text { Cardiovascular } \\
\text { health } \\
\text { study } \|^{\star * 11}\end{array}$ & Cross sectional & - & Stroke & 2050 & 1.4 (0.7 to 2.6$)$ & 1.2 (0.6 to 2.4) & $1.1(0.7$ to 1.8$)$ & 2.0 (1.1 to 3.6$)$ & Not reported \\
\hline $\begin{array}{l}\text { Shibata } \\
{\text { study }{ }^{29}}^{29}\end{array}$ & $\begin{array}{l}\text { Population } \\
\text { based }\end{array}$ & 15.5 & Stroke & 2302 & Not reported & Not reported & Not reported & Not reported & $\begin{array}{c}\text { Men } 3.4(1.0 \text { to } \\
11.3)\end{array}$ \\
\hline
\end{tabular}

*Lowest versus highest quintile of the arteriovenous ratio, using computerised method.

tKeith, Wagener, and Barker classification.

†Multivariate analysis adjusted for age, ethnicity, blood pressure or use of antihypertensive drugs, diabetes, cholesterol, and smoking.

$\S 0$ dds ratios $(95 \% \mathrm{Cls})$.

१Multivariate analysis adjusted for age, ethnicity, and blood pressure or use of antihypertensive drugs.

**People with diabetes excluded. 


\section{What is already known on this topic}

Funduscopy is recommended in the routine management of hypertensive patients

The usefulness of funduscopy is being questioned What this study adds

Funduscopy is of limited additional value in hypertensive patients, unless a hypertensive emergency is suspected

the association with retinopathy significant and consistent. This association is also observed in people without hypertension and is not corrected for other indicators of hypertensive organ damage. Hence the additional value of funduscopy in the management of patients with hypertension still needs to be determined.

The included studies have several limitations. Firstly, in all the studies hypertensive retinopathy was established on a photograph of one eye. As hypertension is a systemic disease, retinal changes would be expected in both eyes. Some retinal abnormalities may thus have been a sign of unilateral eye disease instead of hypertension. Secondly, most of the studies used a broad definition for hypertensive retinopathy, including microaneurysms, hard exudates, and blot haemorrhages. These are not included in the original classification and may have a different association with hypertension. Thirdly, hypertension may have been misclassified, as blood pressure was measured only once or twice. Fourthly, people with diabetes were included in the atherosclerosis risk in communities study and Beaver Dam eye study. Diabetic retinopathy is a known risk factor for cardiovascular disease and may have confounded the association between hypertensive retinopathy and cardiovascular risk. Multivariate analysis may not have totally accounted for this effect. Finally, only middle aged and older people were included in the studies, although the association between hypertensive retinopathy, blood pressure, and risk of cardiovascular disease gets stronger in those under $60 .{ }^{27}$ Future research should consider a younger population ( $<60$ years) and other indicators of hypertensive organ damage.

We thank the division of internal medicine and the library staff of the Academic Medical Centre for their support in the preparation of this review. Contributors: BJHvdB and JBLH conceived the review. BJHvdB and CAAH retrieved and analysed the data and wrote the review. ROS interpreted the data, helped draft the review, and gave critical comments. JBLH and GAvM helped draft and review the review. GAvM will act as guarantor.

Funding: None.

Competing interests: None declared.

Ethical approval: Not required.

1 Klein R, Klein BE, Moss SE, Wang Q. Hypertension and retinopathy, arteriolar narrowing, and arteriovenous nicking in a population. Arch Ophthalmol 1994;112:92-8

2 Klein R. Retinopathy in a population-based study. Trans Am Ophthalmol So 1992;90:561-94

3 Chobanian AV, Bakris GL, Black HR, Cushman WC, Green LA, Izzo JL Jr, et al. The seventh report of the joint national committee on prevention, detection, evaluation, and treatment of high blood pressure: the JNC 7 report. JAMA 2003;289:2560-72.

4 Cifkova R, Erdine S, Fagard R, Farsang C, Heagerty AM, Kiowski W, et al. Practice guidelines for primary care physicians: $2003 \mathrm{ESH} / \mathrm{ESC}$ hypertension guidelines. guidelines for primary care
J Hypertens 2003;21:1779-86.

5 Landis JR, Koch GG. The measurement of observer agreement for categorical data. Biometrics 1977;33:159-74.

6 Higgins JP, Thompson SG, Deeks JJ, Altman DG. Measuring inconsistency in meta-analyses. BMJ 2003;327:557-60.

7 Cuspidi C, Salerno M, Salerno DE, Meani S, Valerio C, Esposito A, et al. High prevalence of retinal vascular changes in never-treated essential hypertensives: an inter- and intra-observer reproducibility study with non-mydriatic retinography. Blood Press 2004;13:25-30

8 Couper DJ, Klein R, Hubbard LD, Wong TY, Sorlie PD, Cooper LS, et al. Reliability of retinal photography in the assessment of retinal microvascular characteristics: the atherosclerosis risk in communities study. Am J Ophthalmol 2002;133:78-88.

9 Hubbard LD, Brothers RJ, King WN, Clegg LX, Klein R, Cooper LS, et al. Methods for evaluation of retinal microvascular abnormalities associated with hypertension/ sclerosis in the atherosclerosis risk in communities study. Ophthalmology 1999;106:2269-80.

10 Sharp PS, Chaturvedi N, Wormald R, McKeigue PM, Marmot MG, Young SM. Hypertensive retinopathy in Afro-Caribbeans and Europeans. Prevalence and risk factor relationships. Hypertension 1995;25:1322-5.

11 Wong TY, Klein R, Sharrett AR, Manolio TA, Hubbard LD, Marino EK, et al. The prevalence and risk factors of retinal microvascular abnormalities in older persons: the carlence and risk factors of retinal microvascular abnormalities
diovascular health study. Ophthalmology 2003;110:658-66.

diovascular health study. Ophthalmology 2003;110:658-66.
12 Yu T, Mitchell P, Berry G, Li W, Wang JJ. Retinopathy in older persons without diabetes and its relationship to hypertension. Arch Ophthalmol 1998;116:83-9.

13 Leung H, Wang JJ, Rochtchina E, Tan AG, Wong TY, Klein R, et al. Relationships between age, blood pressure, and retinal vessel diameters in an older population. Invest Ophthalmol Vis Sci 2003;44:2900-4.

14 Wong TY, Hubbard LD, Klein R, Marino EK, Kronmal R, Sharrett AR, et al. Retinal microvascular abnormalities and blood pressure in older people: the cardiovascular health study. Br J Ophthalmol 2002;86:1007-13.

15 Wong TY, Klein R, Couper DJ, Cooper LS, Shahar E, Hubbard LD, et al. Retinal microvascular abnormalities and incident stroke: the atherosclerosis risk in communities study. Lancet 2001;358:1134-40.

16 Wang JJ, Mitchell P, Leung H, Rochtchina E, Wong TY, Klein R. Hypertensive retinal vessel wall signs in a general older population: the Blue Mountains eye study. Hypertension 2003;42:534-41

17 De Leonardis V, Becucci A, De Scalzi M, Cinelli P. Low incidence of cardiac hypertrophy in essential hypertensives with no retinal changes. Int J Cardiol 1992;35:95-9.

18 Pontremoli R, Sofia A, Ravera M, Nicolella C, Viazzi F, Tirotta A, et al. Prevalence and clinical correlates of microalbuminuria in essential hypertension: the MAGIC Study. Microalbuminuria: a Genoa investigation on complications. Hypertension 1997:30:1135-43.

19 Pose-Reino A, Gonzalez-Juanatey JR, Pastor C, Mendez I, Estevez JC, Alvarez D, et al. Clinical implications of white coat hypertension. Blood Press 1996;5:264-73.

20 Saitoh M, Matsuo K, Nomoto S, Kondoh T, Yanagawa T, Katoh Y, et al. Relationship between left ventricular hypertrophy and renal and retinal damage in untreated patients with essential hypertension. Intern Med 1998;37:576-80.

21 Wong TY, Klein R, Duncan BB, Nieto FJ, Klein BE, Couper DJ, et al. Racial differences in the prevalence of hypertensive retinopathy. Hypertension 2003;41:1086-91.

22 Biesenbach G, Zazgornik J. High prevalence of hypertensive retinopathy and coronary heart disease in hypertensive patients with persistent microalbuminuria under short intensive antihypertensive therapy. Clin Nephrol 1994;41:211-8.

23 Ikram MK, de Jong FJ, Vingerling JR, Witteman JC, Hofman A, Breteler MM, et al. Are retinal arteriolar or venular diameters associated with markers for cardiovascular disorders? The Rotterdam Study. Invest Ophthalmol Vis Sci 2004;45:2129-34.

24 Wong TY, Klein R, Sharrett AR, Couper DJ, Klein BE, Liao DP, et al. Cerebral white matter lesions, retinopathy, and incident clinical stroke. JAMA 2002;288:67-74.

25 Duncan BB, Wong TY, Tyroler HA, Davis CE, Fuchs FD. Hypertensive retinopathy and incident coronary heart disease in high risk men. Br J Ophthalmol 2002;86:1002-6.

26 Gillum RF. Retinal arteriolar findings and coronary heart disease. Am Heart $J$ 1991;122:262-3.

27 Wong TY, Klein R, Nieto FJ, Klein BE, Sharrett AR, Meuer SM, et al. Retinal microvascular abnormalities and 10-year cardiovascular mortality: a population-based casecontrol study. Ophthalmology 2003;110:933-40.

28 Wong TY, Klein R, Sharrett AR, Duncan BB, Couper DJ, Tielsch JM, et al. Retinal arteriolar narrowing and risk of coronary heart disease in men and women. The atherosclerosis risk in communities study. JAMA 2002;287:1153-9.

29 Nakayama T, Date C, Yokoyama T, Yoshiike N, Yamaguchi M, Tanaka H. A 15.5-year follow-up study of stroke in a Japanese provincial city. The Shibata study. Stroke 1997:28:45-52.

30 Yu T, Mitchell P, Berry G, Li W, Wang JJ. Retinopathy in older persons without diabetes and its relationship to hypertension. Arch Ophthalmol 1998;116:83-9.

31 Klein R, Sharrett AR, Klein BE, Chambless LE, Cooper LS, Hubbard LD, et al. Are retinal arteriolar abnormalities related to atherosclerosis?: the atherosclerosis risk in communities study. Arterioscler Thromb Vasc Biol 2000;20:1644-50.

32 Wong TY, Knudtson MD, Klein R, Klein BE, Hubbard LD. A prospective cohort study of retinal arteriolar narrowing and mortality. Am J Epidemiol 2004;159:819-25.

33 Liao D, Wong TY, Klein R, Jones D, Hubbard L, Sharrett AR. Relationship between carotid artery stiffness and retinal arteriolar narrowing in healthy middle-aged carotid artery stiffness and ret

34 Wong TY, Mitchell P. Hypertensive retinopathy. N Engl J Med 2004;351:2310-7. (Accepted 19 May 2005)

bmj.com 2005;331:73

Department of Internal Medicine, Academic Medical Centre, PO 22660, 1100 DD Amsterdam, Netherlands

Bert-Jan $\mathrm{H}$ van den Born research fellow

Joost B L Hoekstra professor

Gert A van Montfrans associate professor

Department of Ophthalmology, Academic Medical Centre, Amsterdam

Caroline A A Hulsman research fellow

Reinier O Schlingemann associate professor

Correspondence to: B-J H van den Born b.j.vandenborn@amc.uva.nl 